\title{
Evaluation of Biosourced Alkyd Nanoemulsions as Drug Carriers
}

\author{
Siew Yong Teo, ${ }^{1}$ Siang Yin Lee, ${ }^{2}$ Huey Lin Ong, ${ }^{2}$ Ching Lin Ong, ${ }^{2}$ Seng Neon Gan, \\ Michael J. Rathbone, ${ }^{1,4}$ and Allan G. A. Coombes ${ }^{2}$ \\ ${ }^{1}$ School of Postgraduate Studies and Research, International Medical University, No. 126, Jalan Jalil Perkasa 19, Bukit Jalil, \\ 57000 Kuala Lumpur, Malaysia \\ ${ }^{2}$ School of Pharmacy, International Medical University, No. 126, Jalan Jalil Perkasa 19, Bukit Jalil, 57000 Kuala Lumpur, Malaysia \\ ${ }^{3}$ Department of Chemistry, Faculty of Science, University of Malaya, Lembah Pantai, 50603 Kuala Lumpur, Malaysia \\ ${ }^{4}$ ULTI Pharmaceuticals, 19 Pembroke Street, Hamilton Lake, Hamilton 3204, New Zealand \\ Correspondence should be addressed to Siang Yin Lee; siang-yinlee@imu.edu.my
}

Received 27 August 2015; Accepted 15 October 2015

Academic Editor: Michele Laus

Copyright (C) 2015 Siew Yong Teo et al. This is an open access article distributed under the Creative Commons Attribution License, which permits unrestricted use, distribution, and reproduction in any medium, provided the original work is properly cited.

Novel oil-in-water $(\mathrm{O} / \mathrm{W})$ nanoemulsions were formulated using short, medium, and long oil length alkyds synthesized from palm kernel oil by a two-stage alcoholysis-polyesterification reaction. Alkyd/surfactant/water ternary phase diagrams identified a composition of $1 \%$ alkyd, $9 \%$ Tween 80 , and $90 \%$ water where spontaneous production of nanoemulsions occurred. The $\mathrm{pH}$, droplet size, and zeta potential of all formulations were in the range of $6.4-6.6,11-14 \mathrm{~nm}$, and $-6 \mathrm{mV}$ to $-8 \mathrm{mV}$, respectively. Rheological studies showed that the nanoemulsions displayed non-Newtonian shear thinning behavior at low shear rates up to $20 \mathrm{~s}^{-1}$ with conversion to Newtonian behavior above this shear rate. All nanoemulsions were found to be stable against phase separation on storage at $4^{\circ} \mathrm{C}$ and $25^{\circ} \mathrm{C}$ for three months. Short oil length alkyd nanoemulsions exhibited significantly higher stability compared with medium and long oil length alkyd nanoemulsions, as demonstrated by an absence of phase separation and only minor changes of droplet size on storage at an elevated temperature of $45^{\circ} \mathrm{C}$ for 3 months. The drug carrying capacity and storage stability of the nanoemulsions were assessed using phenytoin. The entrapment efficiency of alkyd nanoemulsions was in excess of $90 \%$ and loss of phenytoin content was restricted to less than $4 \%$ during storage of the nanoemulsions for three months at $4^{\circ} \mathrm{C}, 25^{\circ} \mathrm{C}$, and $45^{\circ} \mathrm{C}$. Taken together, these findings indicate that nanoemulsions prepared from palm kernel oil-based alkyds offer potential as nanocarriers for drug delivery applications.

\section{Introduction}

Alkyds (vegetable oil modified polyesters) are typically synthesized from a polybasic acid, a polyhydric alcohol, and a triglyceride oil or its fatty acids. Alkyds are conventionally applied in the manufacture of paints, adhesives, inks, and various coatings and are generally classified as short $(<45 \%$ oil content in formulation), medium (45-55\%), or long ( $>55 \%$ ) oil length alkyds. Research on alkyds has generally focused on the different types of vegetable oils used in their preparation, such as linseed, soybean, African locust bean seed, and rubber seed oil [1-3]. Alkyds synthesized from palm oil have been investigated extensively by Gan et al. for various industrial applications [4-7]. Previous studies have also demonstrated the potential advantages of palm oil-based formulations for wound repair, for treatment of skin conditions including skin infections, and for regulation of the body temperature of patients in the control of high fever and convulsion [8-10]. However, there is a marked absence of information on the use of palm oil-based alkyds for pharmaceutical applications.

The lipid component of alkyds suggests their utility as micro- and nanoemulsions for drug delivery. In particular, oil-in-water nanoemulsions are attracting major interest for oral administration and topical applications [11-13]. Borhade et al. found that nanoemulsions greatly enhanced the solubility of clotrimazole to a level of $25 \mathrm{mg} / \mathrm{mL}$ and showed $100 \%$ drug release within 15 minutes irrespective of $\mathrm{pH}$ of medium [11]. Jain et al. demonstrated that nanoemulsions significantly enhanced the oral bioavailability of atorvastatin by more than 2.8- and 2.4-fold compared with conventional tablet and suspension dosage forms, respectively [12]. Alam 
and coworkers reported that nanoemulsion formulations of clobetasol propionate were advantageous for topical delivery to the skin since they were not irritant and reduced inflammation by $84 \%$ in the rat model compared with commercial cream formulations (41\%) [13].

Nanoemulsions are typically transparent, kinetically stable disperse systems, comprising oil droplets of size less than $100 \mathrm{~nm}$ dispersed in an aqueous continuous phase. They are frequently formulated using high-pressure homogenization methods. However, the extreme processing conditions of high pressure and high shear stress coupled with relatively high temperatures may lead to structural and thermal degradation of the drug carrier (excipient) and the incorporated drug [14]. As a result, emulsion phase inversion (EPI) methods have attracted increasing interest for the production of drug-loaded nanoemulsions. EPI requires low energy input and relies on the spontaneous formation of droplets when certain combinations of oil, water, and surfactant are combined under controlled conditions. EPI has been shown to form monodispersed emulsions of very fine droplets with good storage stability [15-17]. For example, Sun et al. reported that bovine serum albumin- (BSA-) loaded nanoemulsions formulated by EPI exhibited a droplet size of approximately $22 \mathrm{~nm}$ and the BSA content was retained for 180 days at room temperature [16].

Nanoemulsions generally incorporate a surfactant to produce an interfacial film around the dispersed oil droplets causing steric repulsion, preventing coalescence, and thus producing stable nanoemulsions [18]. The stability of nanoemulsions is a key determinant of their utility for pharmaceutical manufacture and is generally dictated by the integrity and density of the stabilizing interfacial film at the droplet surface. Nanoemulsion instability may result from a number of interrelated factors including the chemical composition of the stabilizing film, $\mathrm{pH}$ of the continuous phase, and storage temperature [19]. Several studies have highlighted the tendency of nanoemulsions to destabilize under conditions involving steric or electrostatic mechanisms. Nikiforidis et al. found that both steric and electrostatic repulsive forces contributed to the stability of nanoemulsions, by counteracting van der Waals attractive forces [20]. de Morais et al. also concluded that that the stability of canola oil/water nanoemulsions involved electrostatic and steric mechanisms, but the steric contribution was dominant [21].

The aim of this study was to evaluate the potential of novel nanoemulsions based on palm kernel oil-derived alkyds as drug delivery systems for oral and topical applications and to determine the storage stability of drug-loaded formulations. Optimum EPI conditions were established using ternary phase diagrams and the physicochemical characteristics of the resultant nanoemulsions were determined to assess their suitability as drug delivery vehicles. The drug loading capacity, encapsulation efficiency, and long-term storage stability of drug-loaded alkyd nanoemulsions were investigated using the hydrophobic drug, phenytoin.

\section{Materials and Methods}

2.1. Materials. Glycerol, toluene, potassium hydrogen phthalate, phenolphthalein, and Tween 80 were purchased from Fisher Scientific Sdn. Bhd., Selangor, Malaysia. Sebacic acid, ethanol, and potassium hydroxide were purchased from Merck Sdn. Bhd., Selangor, Malaysia. Palm kernel oil (PKO) was received as a gift from IFFCO (S.E.A) Sdn. Bhd., Kuala Lumpur, Malaysia. Phenytoin was purchased from Chemolab Sdn. Bhd., Kuala Lumpur, Malaysia. The chemicals were of reagent grade and used as received.

2.2. Synthesis and Characterization of Alkyds. Short, medium, and long oil length alkyds (designated as SOA, MOA, and LOA, resp.) were synthesized from palm kernel oil, glycerol, and sebacic acid using the two-stage alcoholysispolyesterification method. The reaction was carried out in a reaction flask equipped with a mechanical agitator, thermometer, nitrogen gas inlet, and Dean-Stark decanter. In brief, PKO and glycerol were reacted to form monoglyceride during alcoholysis with the presence of sodium hydroxide $(\mathrm{NaOH}, 0.1 \% \mathrm{w} / \mathrm{w})$ as a catalyst at a temperature of $240 \pm$ $5^{\circ} \mathrm{C}$. Subsequently, sebacic acid was added to the mixture to initiate the second polyesterification stage, which was carried out at $225 \pm 5^{\circ} \mathrm{C}$ to form alkyd.

The acid number and hydroxyl number of the alkyd were determined according to ASTM D4274-05 and ASTM D198087(1998) standard test methods, respectively. Both tests were carried out in triplicate and the average results were reported.

2.3. Formulation of Nanoemulsions. Alkyd nanoemulsions were formulated from the palm kernel oil-derived alkyds, the nonionic surfactant (Tween 80), and ultrapure water at ambient temperature using the EPI method. The oil phase (SOA, MOA, and LOA, resp.) and Tween 80 were weighed separately and mixed thoroughly by vortexing at $1400 \mathrm{rpm}$ for 2 minutes in specific alkyd/surfactant ratios (range of $1: 9$ to $9: 1$ ), to yield mixtures of a constant weight of $1 \mathrm{~g}$. Subsequently, the mixture was slowly titrated with $100 \mu \mathrm{L}$ aliquots $(0.1 \mathrm{~g})$ of ultrapure water. Following each water addition, the mixture was vortexed at $1400 \mathrm{rpm}$ for 2 minutes and visually inspected for changes in appearance and phase separation. Ternary phase diagrams were constructed using the Chemix School v3.50 software (Arne Standnes, Norway).

Phenytoin-loaded alkyd nanoemulsions were formulated by first mixing phenytoin into the mixture of alkyd and surfactant at room temperature. The mixture was vortexed thoroughly at $1400 \mathrm{rpm}$, until a clear dispersion was formed, indicating that drug solubilization was complete. The mixture was slowly titrated with ultrapure water using the EPI method as described above until a nanoemulsion was obtained.

\subsection{Characterization of Nanoemulsions}

2.4.1. Physicochemical Evaluation. The alkyd nanoemulsions were subjected to visual inspection, $\mathrm{pH}$, zeta potential, and droplet size determinations. The zeta potential and droplet size of nanoemulsions were measured using a Zetasizer ZEN 3600 (Malvern, Worcestershire, UK) at room 


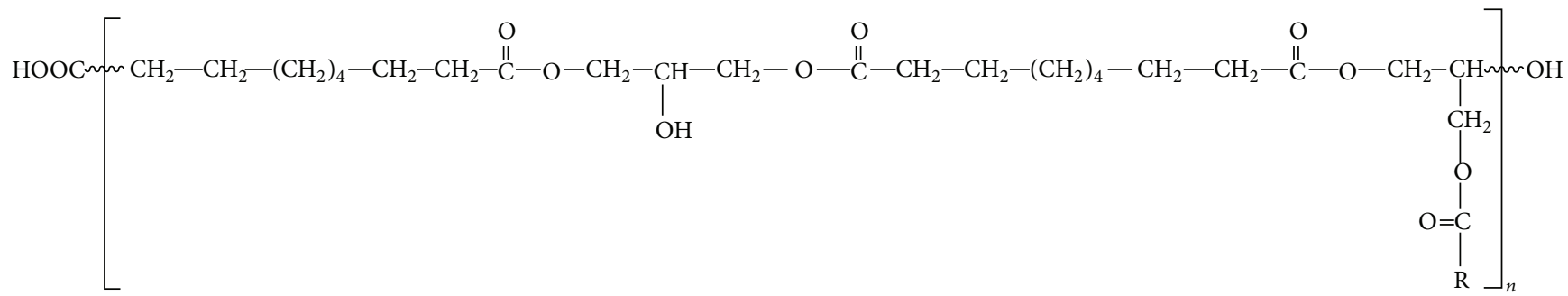

FIGURE 1: Plausible chemical structure of a section of the alkyd chain, where $\mathrm{R}$ is alkyl group.

temperature $\left(25 \pm 1^{\circ} \mathrm{C}\right)$. The instrument was calibrated using zeta potential standard and polystyrene latex standard, respectively. Zeta potential measurements were determined using electrophoretic light scattering (ELS). Droplet size measurements were determined using dynamic light scattering (DLS). All measurements were performed in triplicate.

2.4.2. Rheology. The rheological behavior of nanoemulsions was investigated using a MCR 301 rheometer (Anton Paar, Österreich, Austria) with a concentric cylinder system operating in rotational mode. Nanoemulsion samples $(10 \mathrm{~mL})$ were tested at a controlled temperature of $25 \pm 2^{\circ} \mathrm{C}$ under shear rate control conditions within the range $1 \mathrm{~s}^{-1}$ to $50 \mathrm{~s}^{-1}$. Rheograms of apparent viscosity against shear rate were plotted and the data obtained were fitted to the power law model according to the following equation:

$$
\tau=K \dot{\gamma}^{n}
$$

where $\tau$ is the shear stress, $\dot{\gamma}$ is the shear rate, $K$ is the consistency index $\left(\mathrm{Pa} \cdot \mathrm{s}^{n}\right)$, and $n$ is the flow behavior index.

2.4.3. Emulsion Stability. Nanoemulsion samples were stored in an incubator (Heraeus, Hanau, Germany) at temperatures of $4 \pm 2^{\circ} \mathrm{C}, 25 \pm 2^{\circ} \mathrm{C}$, and $45 \pm 2^{\circ} \mathrm{C}$ for three months. The physical appearance, $\mathrm{pH}$, droplet size, and zeta potential were recorded for triplicate samples at monthly intervals.

2.4.4. Drug Loading, Entrapment Efficiency, and Stability. The drug loading and entrapment efficiency of alkyd nanoemulsions were determined using a high performance liquid chromatography (HPLC) method [22]. The test facility employed a reverse phase HPLC system (1200 series, Agilent Technologies) equipped with a pump, injector valve with $20 \mu \mathrm{L}$ sample loop, ZORBAX Eclipse Plus C-18 analytical column (250 $\mathrm{mm} \times 4.6 \mathrm{~mm}, 5 \mu \mathrm{m}$ particles), and UV detector with data processor (Chem Station Software). The mobile phase of acetonitrile and ultrapure water $(50: 50)$ was delivered at a flow rate of $1.0 \mathrm{~mL} / \mathrm{min}$. Aliquots of samples (phenytoin in alkyd nanoemulsion) were dispersed in the mobile phase and the injected sample volume was $20 \mu \mathrm{L}$. A standard curve of peak area against concentration of phenytoin was plotted and the drug content of each sample was determined by comparison with the standard curve. The following equation was used to calculate the percentage drug loading and encapsulation efficiency of the nanoemulsion:

$$
\begin{aligned}
& \text { Drug loading }(\%)=\frac{\text { Total weight of drug }}{\text { Total weight of sample }} \times 100 \% \text {, } \\
& \text { Entrapment efficiency }(\%) \\
& \qquad=\frac{\text { Actual drug loading }}{\text { Theoretical drug loading }} \times 100 \%
\end{aligned}
$$

The stability of phenytoin in the nanoemulsions was determined using the stability-indicating HPLC assay described above. Measurements were carried out using freshly prepared samples and samples stored for three months at $5^{\circ} \mathrm{C}, 25^{\circ} \mathrm{C}$, and $45^{\circ} \mathrm{C}$. Significant differences in drug content between the two groups were assessed using one-way analysis of variance.

\section{Results and Discussion}

3.1. Synthesis and Characterization of Alkyds. SOA, MOA, and LOA were synthesized using the two-stage alcoholysispolyesterification method yielding a family of materials of low molecular weight $(<2000 \mathrm{Da})$ with the chemical composition shown in Figure 1 and properties shown in Table 1. The low acid number (in the range of 5-7) indicates low content of free acid in the samples and suggests that they are suitable for application on the skin as topical drug delivery systems. In addition, the high hydroxyl numbers listed in Table 1 suggest that the PKO-based alkyds would exhibit good adhesive properties for increasing retention on the skin surface. Furthermore, the presence of pendant hydroxyl groups in the alkyd structure (Figure 1) presents opportunities for crosslinking with other materials (e.g., surfactants) to form three-dimensional structures, which may permit further control of drug release rate.

3.2. Formulation of Alkyd Nanoemulsions. Ternary phase diagrams were constructed for mixtures of each type of alkyd (SOA, MOA, and LOA, resp.) with Tween 80 surfactant and water and found to be similar (Figure 2), indicating that the oil length (or content) of the alkyds investigated had no significant effect on the formation of $\mathrm{O} / \mathrm{W}$ nanoemulsions. Three regions of significance were identified: an isotropic phase region (I), homogenous phase region $(\mathrm{H})$, and twophase region $(\mathrm{T})$. The two-phase $(\mathrm{T})$ region identified those alkyd/Tween 80 /water mixtures (typically $<50 \%$ water, $>50 \%$ 
TABLE 1: Properties of alkyds prepared by two-stage alcoholysis-polyesterification method.

\begin{tabular}{lccc}
\hline PKO-based alkyd* & Oil percentage $(\%)$ & Acid number $(\mathrm{mg} \mathrm{KOH} / \mathrm{g})$ & Hydroxyl number $(\mathrm{mg} \mathrm{KOH} / \mathrm{g})$ \\
\hline SOA & 40 & 5 & 352 \\
MOA & 50 & 6 & 307 \\
LOA & 60 & 7 & 241 \\
\hline
\end{tabular}

${ }^{*}$ SOA, MOA, and LOA: short oil length, medium oil length, and long oil length alkyd.

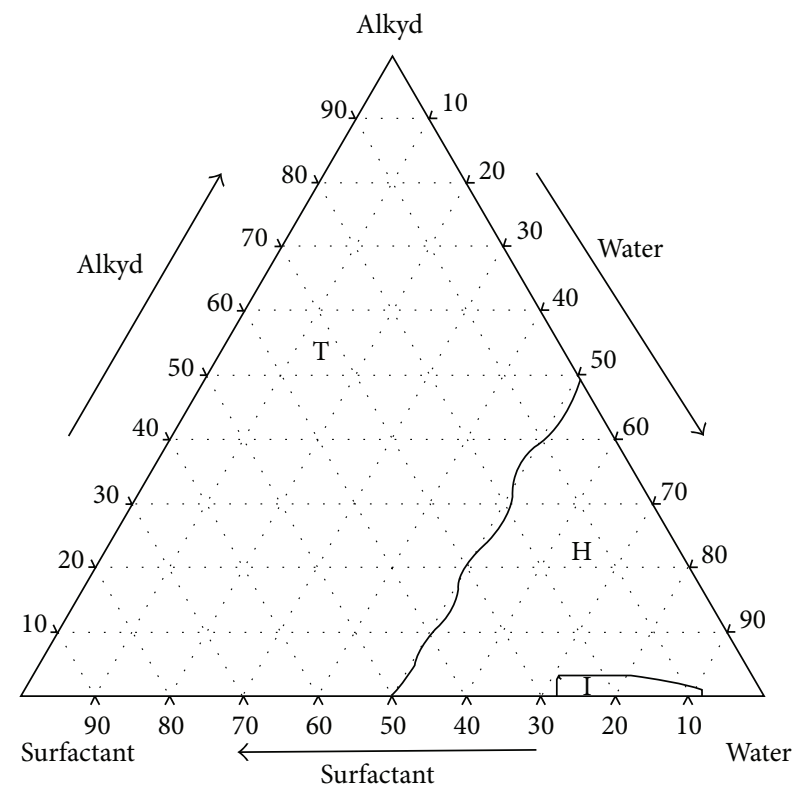

FIGURE 2: Ternary phase diagram formed by Tween 80 (HLB 15.0), short oil length alkyd, and water mixtures. $* \mathrm{~T}, \mathrm{H}$, and I: two-phase region, homogeneous region, and isotropic region.

surfactant) where phase equilibria were not established and constituted the largest part of the phase diagram. This region was a result of the inability of the surfactant to successfully stabilize the alkyd phase. The homogenous phase (H) (typically $>50 \%$ water, $<50 \%$ Tween 80 ) was characterized by a uniform creamy, fluid system. This phase was generally less stable compared with the isotropic region due its high polydispersity. The isotropic phase region (I) (typically $1 \%$ alkyd, 9-29\% Tween 80 , and $70-90 \%$ water) appeared as a transparent, colorless fluid suggesting that the alkyd is solubilized efficiently within the aqueous surfactant phase. Hence, nanoemulsions were formulated from each type of alkyd (SOA, MOA, and LOA) using a composition in the transparent, isotropic region (I) comprising $1 \% \mathrm{w} / \mathrm{w}$ alkyd, $9 \% \mathrm{w} / \mathrm{w}$ Tween 80 , and $90 \%$ ultrapure water (Table 1 ). Incorporation of surfactant is necessary to form an interfacial film around the dispersed alkyd (oil phase) droplets causing steric repulsion, preventing coalescence, and thus producing physical stability. However, nanoemulsion compositions having less than $10 \% \mathrm{w} / \mathrm{w}$ of Tween 80 were selected for further investigation in this study in order to minimize the content of surfactants in formulations that are intended ultimately for clinical application in patients.
TABLE 2: Properties of alkyd nanoemulsions.

\begin{tabular}{|c|c|c|c|c|}
\hline Alkyd type & $\begin{array}{c}\text { Visual } \\
\text { appearance }\end{array}$ & $\mathrm{pH}$ & $\begin{array}{l}\text { Droplet size } \\
(\mathrm{nm})\end{array}$ & $\begin{array}{c}\text { Zeta } \\
\text { potential } \\
(\mathrm{mV})\end{array}$ \\
\hline SOA & $\begin{array}{l}\text { Transparent, } \\
\text { light yellow }\end{array}$ & $6.6 \pm 0.01$ & $12.9 \pm 0.02$ & $-7.9 \pm 0.2$ \\
\hline MOA & $\begin{array}{l}\text { Transparent, } \\
\text { light yellow }\end{array}$ & $6.5 \pm 0.01$ & $12.4 \pm 0.04$ & $-6.1 \pm 0.4$ \\
\hline LOA & $\begin{array}{l}\text { Transparent, } \\
\text { light yellow }\end{array}$ & $6.4 \pm 0.01$ & $11.2 \pm 0.04$ & $-7.2 \pm 0.5$ \\
\hline
\end{tabular}

\subsection{Characterization of Alkyd Nanoemulsions}

3.3.1. Physicochemical Evaluation. The $\mathrm{pH}$ of topical formulations for the skin should be close to the $\mathrm{pH}$ of skin. The $\mathrm{pH}$ of the skin is generally in the range of 4 to 6 , depending mainly on the skin area and the age of the individual; elderly individuals have a skin $\mathrm{pH}$ close to neutral. Alkaline vehicles are known to cause skin irritation and render the skin susceptible to bacterial infection [23]. Lucero et al. recommended that the $\mathrm{pH}$ values of skin formulations should be between 4 and 6.5 to avoid the risk of irritations or alterations of the cutaneous tegmentum [24]. SOA, MOA, and LOA nanoemulsions exhibited a $\mathrm{pH}$ value in the range of 6.4-6.6, indicating that they would not result in irritation, on the basis of a response to acidity/alkalinity, if applied topically on the skin. The alkyd formulations satisfied the size criterion of nanoemulsions (droplets $<100 \mathrm{~nm}$ ) and exhibited a very narrow size range between $11 \mathrm{~nm}$ and $13 \mathrm{~nm}$ (Table 2). Zeta potential measurements carried out on the nanoemulsions (Table 2) provided a measure of the electrical charge carried by the droplets suspended in the aqueous phase. Zeta potential values of all alkyd nanoemulsions ranged between $-6 \mathrm{mV}$ and $-8 \mathrm{mV}$. The small negative charge may be attributed to the hydroxyl groups in the alkyd structure (Figure 1) or the use of the nonionic surfactant (Tween 80) in the formulation and the water dipoles which influence the negative surface charge of the droplets. Marinova et al. reported that the adsorption of hydroxyl ions at an oil-water interface is the most likely mechanism for negative interfacial charging [25]. Overall, the alkyd nanoemulsions may be considered to be almost neutral in terms of electrical charge since the zeta potential results were in the range between $-10 \mathrm{mV}$ and $+10 \mathrm{mV}$ [26].

3.3.2. Rheological Behavior. The viscosity of nanoemulsions affects the ease of distribution and film formation on the skin surface. The change in viscosity of alkyd nanoemulsions as a function of shear rate is shown in Figure 3. The viscosity of all nanoemulsions decreased sharply with increasing shear 
TABLE 3: Rheological properties of alkyd nanoemulsions.

\begin{tabular}{lccc}
\hline Alkyd type & $K$ & $n$ & Maximum viscosity $(\mathrm{mPa} \cdot \mathrm{s})$ \\
\hline SOA & 0.0042 & 0.8157 & 9.26 \\
MOA & 0.0029 & 0.9038 & 4.97 \\
LOA & 0.0021 & 0.9805 & 2.71 \\
\hline
\end{tabular}

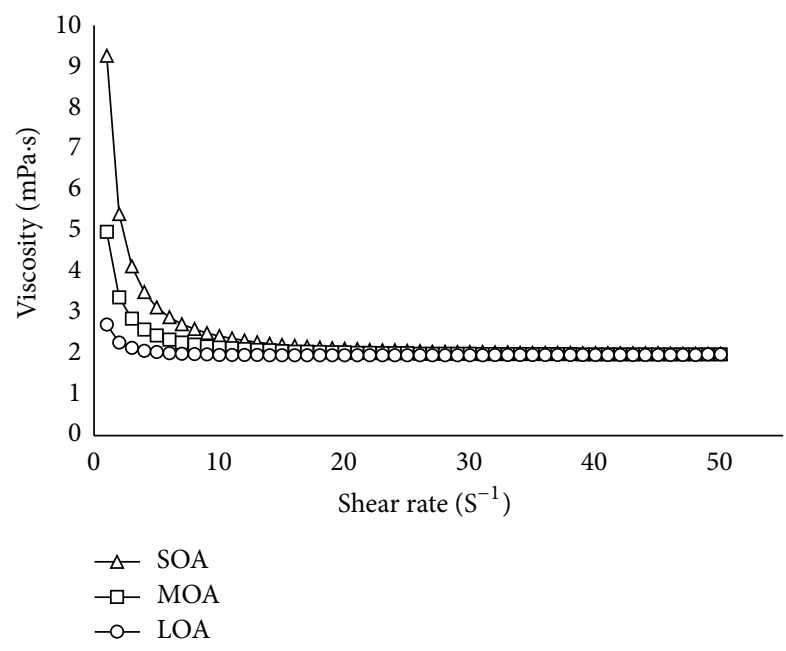

FIGURE 3: Rheological behavior of alkyd nanoemulsions.

rate and then plateaued. The nanoemulsions thus displayed two distinct types of flow behavior, non-Newtonian shearthinning behavior at low shear rates up to $20 \mathrm{~s}^{-1}$ and a transition to Newtonian behavior (identified by constant nanoemulsion viscosity) at higher shear rates up to $50 \mathrm{~s}^{-1}$. The rheological behavior of the nanoemulsions revealed by the rheograms was confirmed by applying the power law model (1). Good data fits were obtained with high correlation coefficients $\left(r^{2}>0.95\right)$. The values of $K$ and $n$ are shown in Table 3. The flow index of all nanoemulsions was less than 1 , which indicated shear-thinning (pseudoplastic) behavior and is indicative of the presence of weak interactions (attractive forces) between the droplets and surrounding aqueous medium. The weak, elastic gel-like network offers a resistance to flow initially under low shear forces, which decreases under increasing shear forces, eventually leading to unrestricted flow of droplets in the direction of the shearing force. The finding of non-Newtonian rheological behavior of the alkyd nanomeulsions at low shear rates below $20 \mathrm{~s}^{-1}$ is comparable with the pseudoplastic behavior of several nanoemusions reported by Jaworska et al. [27].

3.3.3. Nanoemulsion Stability. Nanoemulsions prepared from SOA, MOA, and LOA generally exhibited no visible sign of phase separation over 3 months at storage temperatures of $4^{\circ} \mathrm{C}$ and $25^{\circ} \mathrm{C}$. However, evidence of phase separation (as indicated by precipitate formation) was apparent after 1 month storage at $45^{\circ} \mathrm{C}$ in the case of MOA and LOA nanoemulsions and distinct phase separation occurred between two and three months. It is likely that the elevated temperature imparts higher thermal energy to the droplets, causing an increase in collision frequency, which

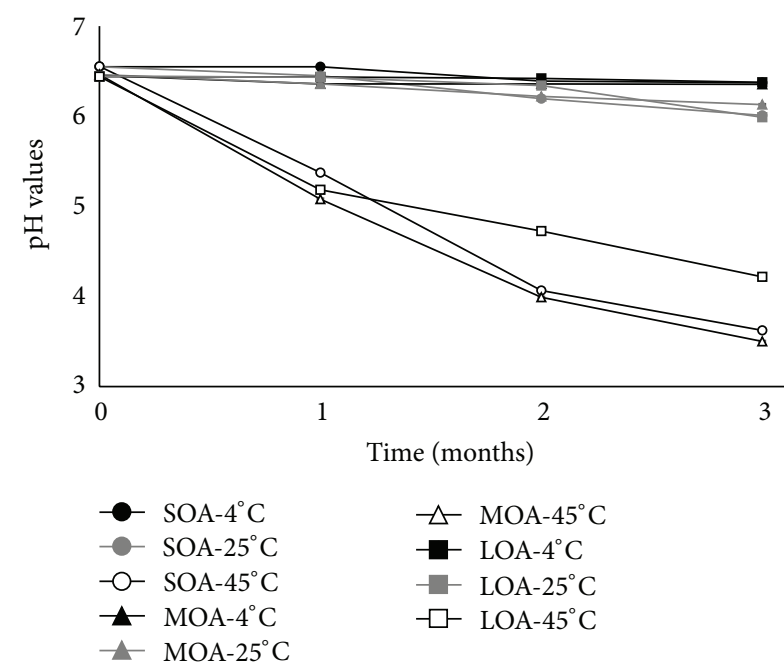

FIGURE 4: Effect of storage time on the $\mathrm{pH}$ of alkyd nanoemulsions stored at $4^{\circ} \mathrm{C}, 25^{\circ} \mathrm{C}$, and $45^{\circ} \mathrm{C}$.

consequently leads to coalescence and phase separation. Interestingly, nanoemulsions prepared from short oil length alkyds remained stable at $45^{\circ} \mathrm{C}$ for 3 months, suggesting that the interfacial surfactant film provides greater resistance to droplet coalescence in this system, possibly due to an increased packing density of surfactant chain molecules at the droplet surface.

All nanoemulsions (SOA, MOA, and LOA) maintained a $\mathrm{pH}$ value between 6.0 and 6.6 during storage for three months at $4^{\circ} \mathrm{C}$ and $25^{\circ} \mathrm{C}$ and there was negligible effect of alkyd oil length (Figure 4). This behavior indicates that the nanoemulsions exhibit high resistance to hydrolytic degradation and are advantageous for the preparation of pharmaceutical formulations. However, there was a significant decrease in $\mathrm{pH}$ of the nanoemulsions from around 6.5 to $3.5-4.2$ on storage at $45^{\circ} \mathrm{C}$ for three months, indicating an increased rate of hydrolysis. Dissolution of degradation products (organic acid monomers) in the water phase at high storage temperature leads to increasing acidity of the nanoemulsion over time.

Zeta potential is widely used to predict the stability of colloidal systems since it indicates the magnitude of the surface charge on particles and thus the degree of repulsion which prevents coalescence. The low zeta potential values $(-6 \mathrm{mV}$ to $-8 \mathrm{mV})$ of the nanoemulsions may arise from spontaneous adsorption of hydroxyl ions $\left(\mathrm{OH}^{-}\right)$from the water phase to the hydrophilic head of surfactants as a result of hydrogen bonding or desorption of hydrogen ions $\left(\mathrm{H}^{+}\right)$from the droplet surface into the water phase to form hydronium ions $\left(\mathrm{H}_{3} \mathrm{O}^{+}\right)$. Therefore, the decrease of absolute zeta potential of all alkyd nanoemulsions with increasing storage time and storage temperature (Figure 5) may indicate a charge neutralization effect between hydroxyl ions $\left(\mathrm{OH}^{-}\right)$ and hydronium ions $\left(\mathrm{H}_{3} \mathrm{O}^{+}\right)$. Generally, charge stabilization of nanoemulsions is considered to be effective if the zeta potential is above $+30 \mathrm{mV}$ or below $-30 \mathrm{mV}$. Stabilization of nanoemulsions prepared using nonionic surfactants including Tween 80 occurs mainly via steric mechanisms [21, 28] 
TABLE 4: Study of drug stability in alkyd nanoemulsions.

\begin{tabular}{|c|c|c|c|c|}
\hline \multirow{2}{*}{ Alkyd nanoemulsion } & \multicolumn{4}{|c|}{ Drug content (\%) of nanoemulsions measured at different temperatures following three-month storage } \\
\hline & Freshly prepared & $4^{\circ} \mathrm{C}$ & $25^{\circ} \mathrm{C}$ & $45^{\circ} \mathrm{C}$ \\
\hline SOA & 100 & 100 & 100 & 98 \\
\hline MOA & 100 & 99 & 99 & 97 \\
\hline LOA & 100 & 99 & 98 & 97 \\
\hline
\end{tabular}

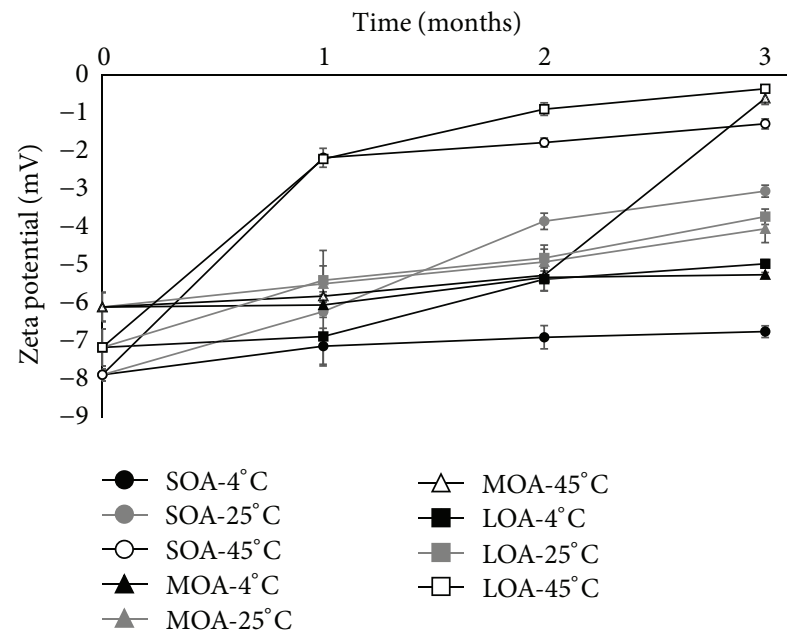

FIGURE 5: Effect of storage time on zeta potential of nanoemulsions stored at $4^{\circ} \mathrm{C}, 25^{\circ} \mathrm{C}$, and $45^{\circ} \mathrm{C}$.

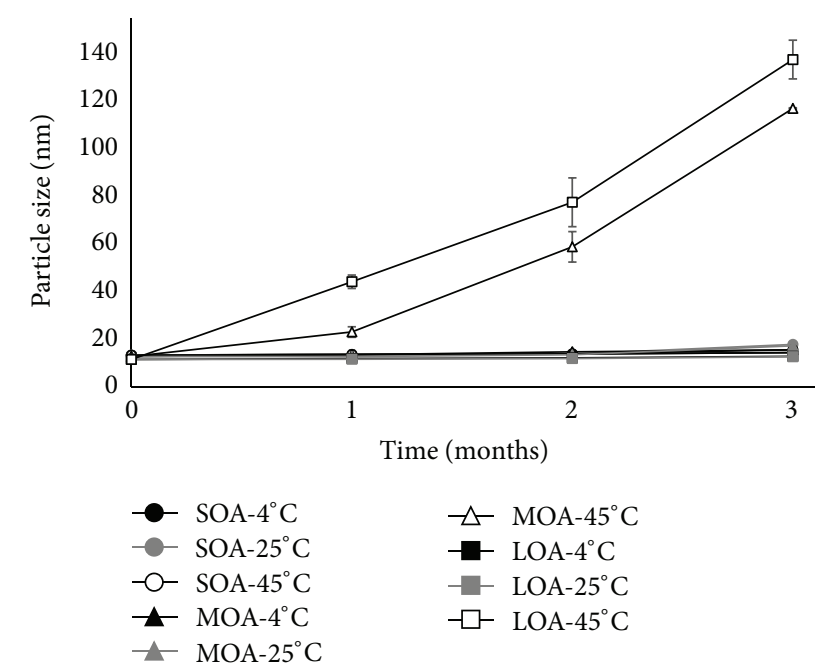

FIGURE 6: Effect of storage time on the droplet size of nanoemulsions stored at $4^{\circ} \mathrm{C}, 25^{\circ} \mathrm{C}$, and $45^{\circ} \mathrm{C}$.

and the low values of zeta potential measured in the present study to support this principle.

The change in droplet size of nanoemulsions prepared from SOA, MOA, and LOA over 3 months at storage temperatures of $4^{\circ} \mathrm{C}, 25^{\circ} \mathrm{C}$, and $45^{\circ} \mathrm{C}$ is presented in Figure 6. The droplet size of all nanoemulsions remained fairly constant at around $12 \mathrm{~nm}$ on storage at $4^{\circ} \mathrm{C}$ for three months, indicating that $4^{\circ} \mathrm{C}$ is a suitable, long-term storage temperature for alkyd nanoemulsions.

A small increase in droplet size from around $12 \mathrm{~nm}$ to $17 \mathrm{~nm}$ was recorded for all alkyd nanoemulsions after 3 months of storage at $25^{\circ} \mathrm{C}$. These minimal changes may be explained by the high surfactant concentration in the nanoemulsions that improves stability by forming a strong interfacial film around the dispersed droplets to impede coalescence. The high surfactant concentration is also expected to lower the rate of droplets ripening by reducing the rate of dissolution of the alkyd in water due to the formation of surfactant micelles that shield the oil droplets from the continuous aqueous phase.

When nanoemulsions were stored at $45^{\circ} \mathrm{C}$ for 3 months, the droplet size of MOA and LOA nanoemulsions increased significantly by a factor of 10 (from approximately $10 \mathrm{~nm}$ to $115-130 \mathrm{~nm}$ ), indicating a decrease in nanoemulsion stability. This behavior may be explained by increases in thermal energy of the droplets in the nanoemulsions and increased collision frequency leading to droplet coalescence. The decrease in stability may also be connected with a decrease in density (or viscosity) of the stabilizing interfacial film with increasing temperature, which results in film-drainage effects and subsequent drop coalescence and instability of the system. Interestingly, the droplet size of SOA nanoemulsion increased by only $17 \%$ when retained at $45^{\circ} \mathrm{C}$ for 3 months, demonstrating improved storage stability compared with MOA and LOA nanoemulsions, in line with visual observations. An increased packing density of surfactant chain molecules at the droplet surface provides a possible explanation for this behavior, as noted previously.

3.3.4. Drug Loading and Entrapment Efficiency of Nanoemulsions. In the present study, phenytoin was incorporated in the three types of alkyd nanoemulsion using the EPI method. Phenytoin is an anticonvulsant drug and rated as a Class II compound under the Biopharmaceutics Classification System (BCS). Such compounds permeate efficiently across biological membranes but have limited aqueous solubility and thus require precise formulation to achieve acceptable levels of oral bioavailability and therapeutic activity. A high drug loading of $10 \mathrm{mg} / \mathrm{mL}$ was measured for alkyd nanoemulsions irrespective of oil length. The encapsulation efficiency of SOA, MOA, and LOA nanoemulsions was calculated as $98.8 \pm 0.9 \%, 97.2 \pm 1.2 \%$, and $92.6 \pm 1.5 \%$, respectively, indicating extremely efficient drug encapsulation within the alkyd nanoemulsions.

3.3.5. Measurement of Drug Stability of Nanoemulsions. No significant change $(P>0.05)$ in the drug content of 
nanoemulsions was measured following storage at $4^{\circ} \mathrm{C}, 25^{\circ} \mathrm{C}$, and $45^{\circ} \mathrm{C}$ for three months when compared with the freshly prepared alkyd nanoemulsions (Table 4 ). This finding indicates absence of drug-alkyd interactions over an extended time period and the absence of drug degradation on storage of nanoemulsions at an elevated temperature of $45^{\circ} \mathrm{C}$.

\section{Conclusions}

Nanoemulsions having a droplet size around $12 \mathrm{~nm}$ were successfully prepared from mixtures of palm kernel oil-derived alkyds and aqueous Tween 80 surfactant using the emulsion phase inversion technique. The nanoemulsions exhibited favorable pharmaceutical characteristics, namely, $\mathrm{pH}$ values around 6.5, pseudoplastic flow behavior, and impressive physical stability on storage at ambient temperature for three months. Furthermore, the alkyd nanoemulsions were capable of efficiently encapsulating a hydrophobic drug, phenytoin, with no significant drug loss on storage at $4^{\circ} \mathrm{C}, 25^{\circ} \mathrm{C}$, and $45^{\circ} \mathrm{C}$ for three months. Alkyd-based nanoemulsions thus show significant potential as drug carriers for topical and oral administration.

\section{Conflict of Interests}

The authors declare no conflict of interests.

\section{Acknowledgments}

This project was funded by International Medical University under Project no. IM130272-95000, Malaysia Toray Science Foundation (MTSF) Science and Technology Grant 2014 (IMUR160/2014), and University of Malaya under Project no. PG050-2014A. The authors thank IFFCO (S.E.A) Sdn. Bhd. for providing $\mathrm{PKO}$ used in this study.

\section{References}

[1] N. Karak, Vegetable Oil-Based Polymers: Properties, Processing and Applications, Elsevier, New York, NY, USA, 2012.

[2] A. I. Aigbodion and F. E. Okieimen, "An investigation of the utilisation of African locust bean seed oil in the preparation of alkyd resins," Industrial Crops and Products, vol. 13, no. 1, pp. 29-34, 2001.

[3] A. I. Aigbodion and C. K. S. Pillai, "Synthesis and molecular weight characterization of rubber seed oil-modified alkyd resins," Journal of Applied Polymer Science, vol. 79, no. 13, pp. 2431-2438, 2001.

[4] S.-N. Gan and B.-Y. Tan, "FTIR studies of the curing reactions of palm oil alkyd-melamine enamels," Journal of Applied Polymer Science, vol. 80, no. 12, pp. 2309-2315, 2001.

[5] S. N. Gan and D. T. C. Ang, "Development of palm oil-based alkyds as UV curable coatings," Pigment \& Resin Technology, vol. 41, no. 5, pp. 302-310, 2012.

[6] S. Ataei, R. Yahya, and S. N. Gan, "Palm oleic acid based alkyds: effect of the fatty acid content on the polyesterification kinetics," Journal of Polymers and the Environment, vol. 19, no. 2, pp. 540545, 2011.
[7] S. Y. Lee and S. N. Gan, "The adhesion properties of natural rubber pressure-sensitive adhesives using palm kernel oil-based alkyd resins as a tackifier," Composite Interfaces, vol. 20, no. 3, pp. 177-188, 2013.

[8] E. E. Ilodigwe, L. U. Ndunagu, D. L. Ajaghaku, and U. A. Utoh-Nedosa, "Evaluation of the wound healing activity of a polyherbal remedy," Annals of Biological Research, vol. 3, no. 11, pp. 5393-5398, 2012.

[9] S. Sasidharan, R. Nilawatyi, R. Xavier, L. Y. Latha, and R. Amala, "Wound healing potential of Elaeis guineensis Jacq leaves in an infected albino rat model," Molecules, vol. 15, no. 5, pp. 31863199, 2010.

[10] O. C. Ugbogu, R. A. Onyeagba, and O. A. Chigbu, "Lauric acid content and inhibitory effect of palm kernel oil on two bacterial isolates and Candida albicans," African Journal of Biotechnology, vol. 5, no. 11, pp. 1045-1047, 2006.

[11] V. Borhade, S. Pathak, S. Sharma, and V. Patravale, "Clotrimazole nanoemulsion for malaria chemotherapy. Part I. Preformulation studies, formulation design and physicochemical evaluation," International Journal of Pharmaceutics, vol. 431, no. 1-2, pp. 138-148, 2012.

[12] K. Jain, R. Suresh Kumar, S. Sood, and K. Gowthamarajan, "Enhanced oral bioavailability of atorvastatin via oil-in-water nanoemulsion using aqueous titration method," Journal of Pharmaceutical Sciences and Research, vol. 5, no. 1, pp. 18-25, 2013.

[13] M. S. Alam, M. S. Ali, N. Alam, M. R. Siddiqui, M. Shamim, and M. Safhi, "In vivo study of clobetasol propionate loaded nanoemulsion for topical application in psoriasis and atopic dermatitis," Drug Invention Today, vol. 5, no. 1, pp. 8-12, 2013.

[14] A. Garud, D. Singh, and N. Garud, "Solid lipid nanoparticles (SLN): method, characterization and applications," International Current Pharmaceutical Journal, vol. 1, no. 11, pp. 384-393, 2012.

[15] D. S. Bernardi, T. A. Pereira, N. R. Maciel et al., "Formation and stability of oil-in-water nanoemulsions containing rice bran oil: in vitro and in vivo assessments," Journal of Nanobiotechnology, vol. 9, no. 44, pp. 1-9, 2011.

[16] H. Sun, K. Liu, W. Liu et al., "Development and characterization of a novel nanoemulsion drug-delivery system for potential application in oral delivery of protein drugs," International Journal of Nanomedicine, vol. 7, pp. 5529-5543, 2012.

[17] Y. Zhang, J. Gao, H. Zheng, R. Zhang, and Y. Han, “The preparation of 3,5-dihydroxy-4-isopropylstilbene nanoemulsion and in vitro release," International Journal of Nanomedicine, vol. 6 , pp. 649-657, 2011.

[18] G. Z. Abdullah, M. F. Abdulkarim, I. M. Salman et al., "Stability studies of nano-scaled emulsions containing ibuprofen for topical delivery," International Journal of Drug Delivery, vol. 3, no. 1, pp. 74-82, 2011.

[19] J. S. Lim, S. F. Wong, M. C. Law, Y. Samyudia, and S. S. B. Dol, "A review on the effects of emulsions on flow behaviours and common factors affecting the stability of emulsions," Journal of Applied Sciences, vol. 15, no. 2, pp. 167-172, 2015.

[20] C. V. Nikiforidis, O. A. Karkani, and V. Kiosseoglou, "Exploitation of maize germ for the preparation of a stable oilbody nanoemulsion using a combined aqueous extractionultrafiltration method," Food Hydrocolloids, vol. 25, no. 5, pp. 1122-1127, 2011.

[21] J. M. de Morais, O. D. H. dos Santos, T. Delicato, and P. A. da Rocha-Filho, "Characterization and evaluation of electrolyte 
influence on canola oil/water nano-emulsion," Journal of Dispersion Science and Technology, vol. 27, no. 7, pp. 1009-1014, 2006.

[22] S. Y. Teo, M. J. Rathbone, A. G. A. Coombes, S. Y. Lee, and S. N. Gan, "Development and validation of a stabilityindicating isocratic reverse phase-liquid chromatography assay for determination of phenytoin in bulk and pharmaceutical formulations," International Journal of Pharmacy and Pharmaceutical Sciences, vol. 7, no. 8, pp. 258-263, 2015.

[23] E. S. Mahdi, A. M. Noor, M. H. Sakeena, G. Z. Abdullah, M. F. Abdulkarim, and M. A. Sattar, "Formulation and in vitro release evaluation of newly synthesized palm kernel oil esters-based nanoemulsion delivery system for $30 \%$ ethanolic dried extract derived from local Phyllanthus urinaria for skin antiaging," International journal of nanomedicine, vol. 6, pp. 2499-2512, 2011.

[24] M. J. Lucero, J. Vigo, and M. J. León, "A study of shear and compression deformations on hydrophilic gels of tretinoin," International Journal of Pharmaceutics, vol. 106, no. 2, pp. 125133, 1994.

[25] K. G. Marinova, R. G. Alargova, N. D. Denkov et al., "Charging of oil-water interfaces due to spontaneous adsorption of hydroxyl ions," Langmuir, vol. 12, no. 8, pp. 2045-2051, 1996.

[26] A. C. Puhl, M. Fagundes, K. C. dos Santos et al., "Preparation and characterization of polymeric nanoparticles loaded with the flavonoid luteolin, by using factorial design," International Journal of Drug Delivery, vol. 3, no. 4, pp. 683-698, 2011.

[27] M. Jaworska, E. Sikora, and J. Ogonowski, "The influence of glicerides oil phase on $\mathrm{O} / \mathrm{W}$ nanoemulsion formation by pic method," Periodica Polytechnica: Chemical Engineering, vol. 58, pp. 43-48, 2014.

[28] N. Anarjan and C. P. Tan, "Effects of selected polysorbate and sucrose ester emulsifiers on the physicochemical properties of astaxanthin nanodispersions," Molecules, vol. 18, no. 1, pp. 768777, 2013. 

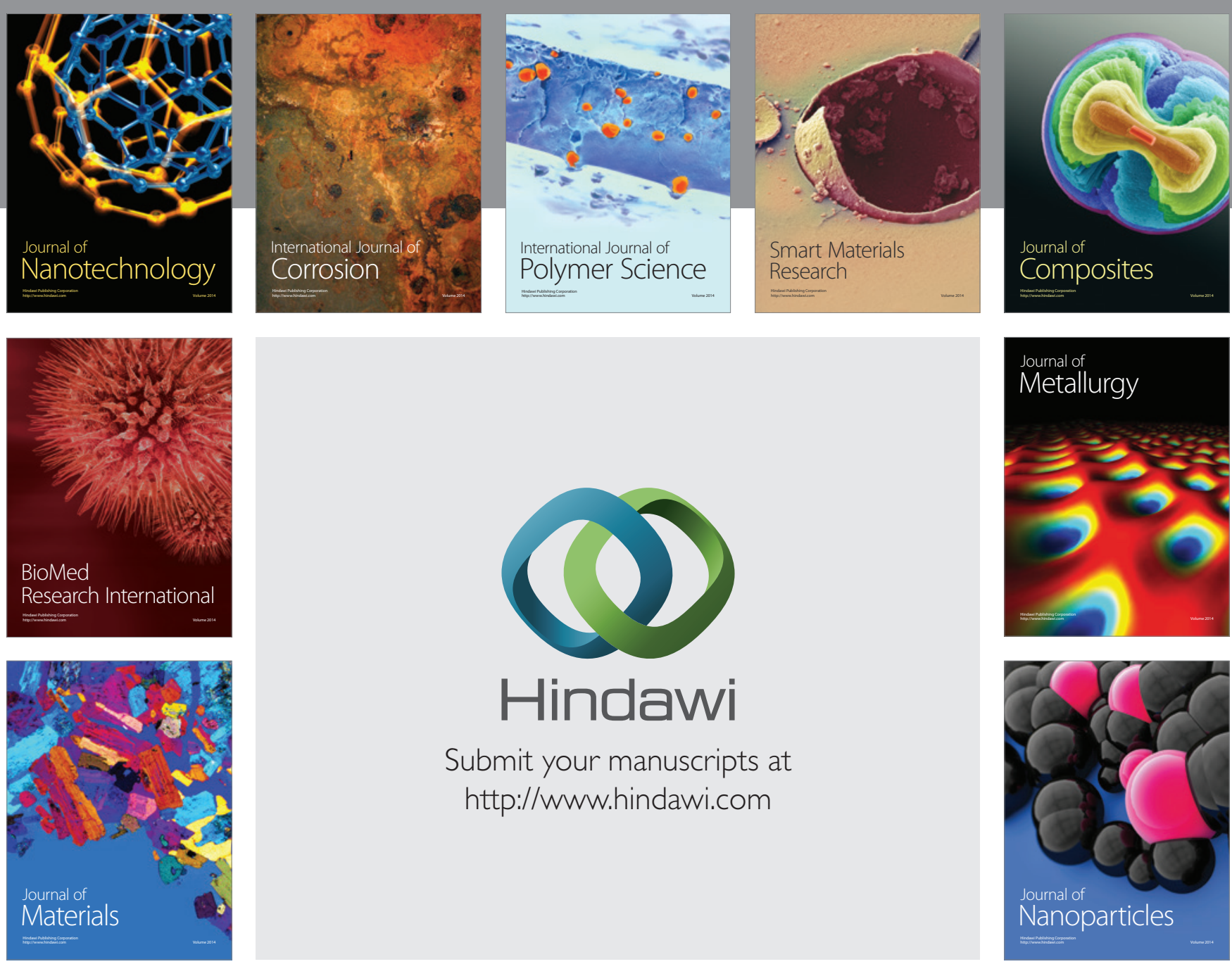

Submit your manuscripts at http://www.hindawi.com
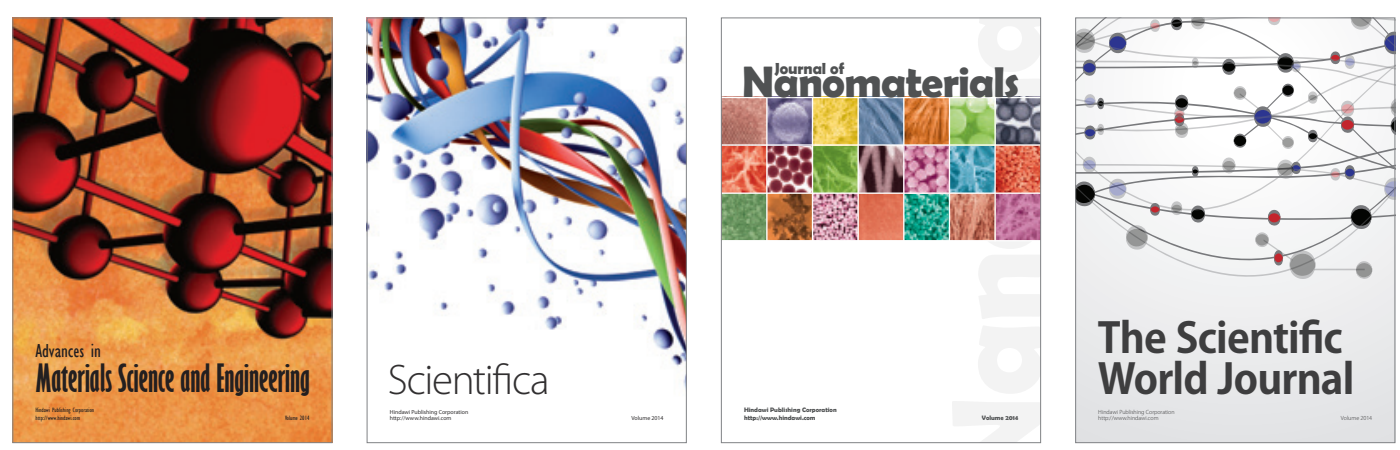

\section{The Scientific World Journal}
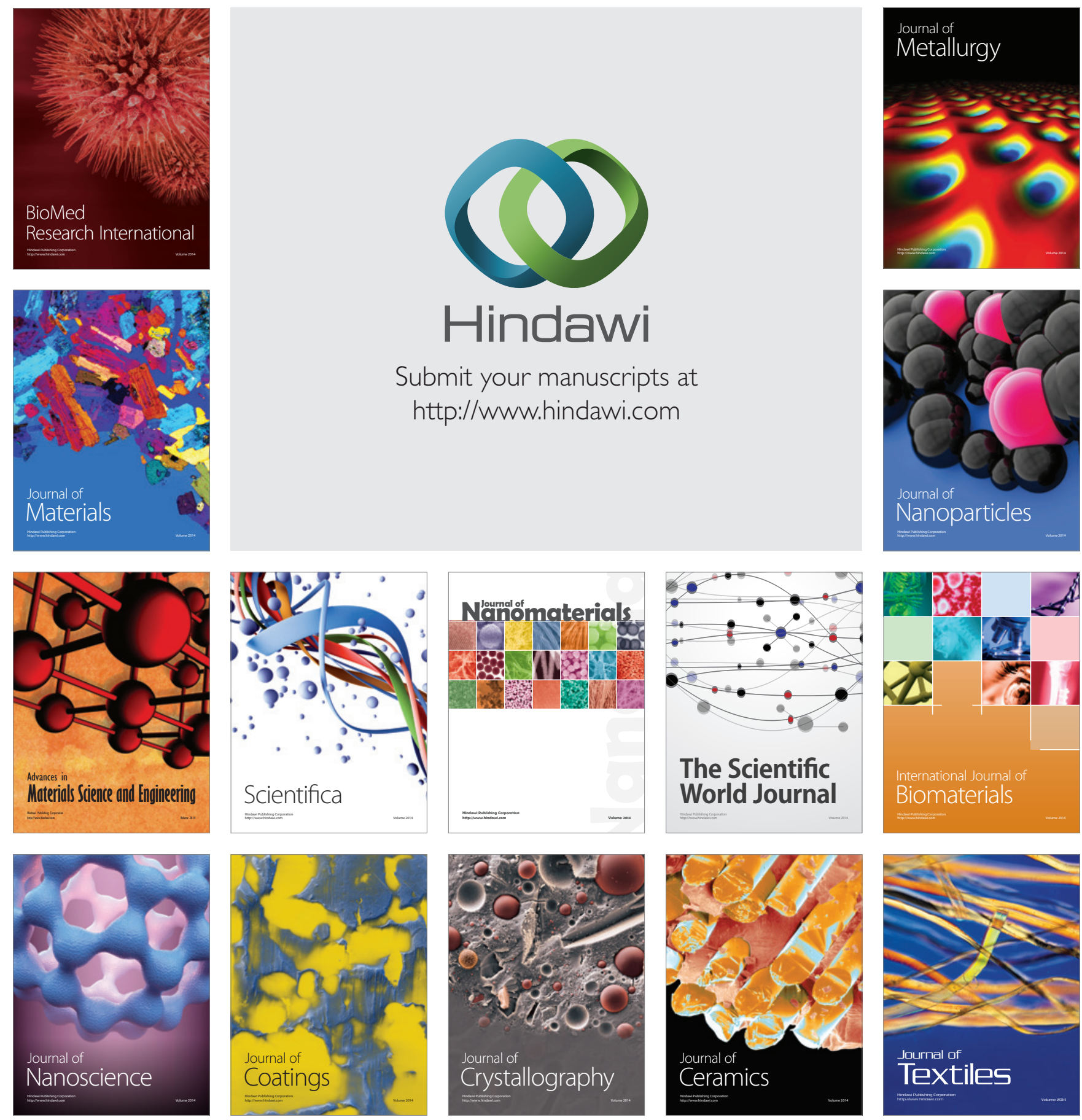